\title{
Construction and Validation of the Scale of Practices and Behaviors of Institutionalized Elderly to Prevent Falls
}

\author{
Cristina Lavareda Baixinho,", , Maria dos Anjos Dixe ${ }^{2}$ \\ ${ }^{1}$ Lisbon Nursing School, Health Research Unit (UIS), Portugal \\ ${ }^{2}$ Leiria Health School, IPL; Health Research Unit (UIS), Portugal
}

Copyright $\mathrm{O} 2016$ by authors, all rights reserved. Authors agree that this article remains permanently open access under the terms of the Creative Commons Attribution License 4.0 International License

\begin{abstract}
Falls are a public health problem, which directly contribute to functional decline, increased dependency and increased complications associated with immobility syndrome. The investigation has been productive in biophysiological identification of risk factors, but less successful to identify environmental risk and even less to identify behavioral risk factors. This methodological study aimed to build and validate an instrument to assess management practices and behaviors for risk of falls. The Scale of Practices and Behaviors for Institutionalized Elderly to Prevent Falls has two dimensions: 1 - communication practices and behaviors between elderly and different professionals from the institution $(\alpha=0.881 ; \mathrm{KMO}=0.775)$, 2- safety practices and behaviors adopted by elderly $(\alpha=0.817 ; \quad \mathrm{KMO}=0.727)$. The instrument has good psychometric characteristics and it can be used for investigation and for clinical practice to identify practices and behaviors related to fall risk.
\end{abstract}

Keywords Falls, Elderly, Nursing Homes, Behaviors and Assessment Scale

\section{Introduction}

Falls are prevalent in the population aged 65 or more. Studies show that the prevalence is higher in elderly residents in nursing homes ${ }^{1-4}$, with $34-67 \%$ of institutionalized elderly having a fall at least once a year.

High occurrence of this phenomenon in nursing homes it is justified by the multiple risk factors ${ }^{3,5}$, the higher dependence level of this population ${ }^{6}$, change of life daily routines with restrictions in carrying out those activities, presence of other residents and practices of different professionals ${ }^{6}$.

Reducing the prevalence of falls is a public health challenge, which involves the identification and control of risk factors and implementation of preventive measures ${ }^{7}$.

For this decrease to happen professionals must be aware and acquire abilities when assessing and controlling risk factors and occurred falls, with elderly in general and, in particular with those living in nursing homes ${ }^{8}$.

The approach to the risk factors and preventive measures of falls has had a very biomedical approach, we need a broader comprehension of this phenomenon, including psychological impact, emotions and new preventive measures ${ }^{9}$ providing literacy of the elderly, changing practices and safety behaviors. WHO (2007) itself warns that research has been more productive on the biological and environmental risk factors than with behavioral risk factors ${ }^{10}$.

Literature research revealed that studies about elderly falls in institutions are more focused in risk factors and preventive measures, and less focused on practices and behaviors.

Due to the magnitude of this question, it appeared relevant the identification of practices and behaviors for fall prevention of the institutionalized elderly, regarding communication and self-care.

The bibliographic research excluded the existence of validated instruments for the effect.

Given the above, this methodological study aimed to build and validate an instrument to assess risk management practices and behaviors for fall in elderly and to verify its psychometric properties.

\section{Methods}

To consolidate the mentioned objectives, we designed a methodological study in two phases: construction of scales (Phase 1) and their psychometric analysis (Phase 2).

\section{Phase 1: Construction of scales}

Taking into account the elderly practices and behaviors in this subject and having a bibliographical research as basis, we decided to build a multidimensional scale constituted by two areas: communication practices and behaviors about risk factors between elderly and institutional professionals and, safety practices and behaviors adopted by elderly. 
Selection of items to include in the instrument

The experts' resource and the data survey from a population similar to our study, and the interviews given to professionals, allowed to know the context and to conjugate with results from the literature review, therefore, defining the items to add in the scale. During a month, we were present in one institution, to observe the elderly and to identify the dependence level, self-care difficulties, and the needs of help from someone else. We registered observations and notes from dialogues in a diary.

To avoid measurement errors, we created the following criteria: clarity, precision, confidence, consistency, semantical adequacy, reliability, utility, validity, and consensus ${ }^{14}$.

\section{Content validity}

After building the first version of the scale, we consulted field experts about the pertinence of items, writing clarity, and context adequacy.

We also conducted a thinking aloud reflection with a group of elderly that was called to pronounce about clarity of questions, difficulties in comprehending items and/or filling them. This thinking aloud reflection allowed to enhance items through shared comments, verification of item's comprehensibility and filling instructions and, the analysis of interpretations ${ }^{15}$.

We conducted a pre-test with 21 elderly to verify instrument comprehension, adequacy of questions, and the Likert type scale. They were asked to appreciate the content and instrument's form, regarding clarity, comprehensibility of items and mean filling time.

Phase 2: Instrument's psychometric analysis

Population and sample

To perform the instrument's psychometric analysis, the defined population was elderly residing in institutions.

To define the sample, we defined the following inclusion criteria: individuals being 65 years of more, without cognitive deficit, of both genders, who freely consented to participate in the study. To assess the cognitive state, we applied the Mini Mental State Examination (MMSE), Portuguese version ${ }^{11}$.

To select the sample size, we used the criteria of 5 respondents per item ${ }^{12,13}$. The sample was composed by 156 elderly residing in 6 institutions, with a response rate of $33.8 \%$ (total sample 462 ).

\section{Instrument}

We built a multidimensional scale with 30 items grouped in 2 dimensions, which we designed as "Practices and Behavior of Institutionalized Elderly for Fall Prevention Scale" ("Escala de Práticas e comportamento dos IdososInstitutionalizados para PrevenirQuedas" EAPCIPQ).

The first dimension is constituted by 7 items and it is about communication practices and behaviors between elderly and different institutional professionals.

Twenty-three items constitute the second dimension, regarding safety practices and behaviors adopted by elderly.

Each item is assessed trough a likert type answer five options ( 1 - never to 5 - always),

Formal and Ethical procedures

This study obtained a favorable opinion from the Ethics Committee of the Universidade Católica Portuguesa. It has submitted an application to the institutions concerned to authorize the development of the research and the presence of one of the researchers for data collection.

Participants were informed about the aims of the study and signed the free and informed consent.

Anonymity and confidentiality was guaranteed during collection, processing and disclosure of data.

We performed data collection in a room or inside the participant's room to preserve privacy and data confidentiality.

\section{Data collection}

After identification of seniors who met the inclusion criteria for this study, the MMSE was applied.

Interviews with elderly were always conducted by the investigator after the free and informed consent was given.

Participants took 30 minutes on average to fill the instrument. We collected data through face-to-face interviews with each elderly.

Data collection occurred during October to December of 2013.

\section{Data treatment}

We tested fidelity through internal consistency analysis, determining the Cronbach's Alpha coefficient ${ }^{13-16}$.

For factorial analysis in main components, we used the Varimax type orthogonal rotation, and the extraction of factors with proper values superior to one. We used the Cattell graph or scree plot to prove the number of factors to be retained (for space reasons, we did not include in the study), and we used the Kaiser-Keyer-Olkin(KMO) test and the Barlett's index to assess the quality of the correlations between variables and to test validity of the factorial matrix 13,16. In the factorial analysis of main components with Varimax rotation, we used interpretability and statistical criteria.

\section{Results}

One-hundred and fifty-six elder individuals composed the sample, $67.3 \%$ were women, and $32.7 \%$ were men, of mean age 81.2 years (SD: 6.7).

Regarding educational level, $29.5 \%$ were illiterate, $29.5 \%$ knew how to read and write but did not complete an educational level, $26.9 \%$ finished the basic level, $8.3 \%$ finished the secondary level, and $5.8 \%$ completed a superior educational course. 
In order to facilitate data reading, we present the psychometric characteristics' assessment of both dimensions. The statistical procedure to determine psychometric characteristics led to elimination of item 1 from the $1^{\text {st }}$ dimension and 12 items from the second.

Dimension 1: Communication practices and behaviors about risk factors between elderly and professionals from the institution

Fidelity

The communication dimension of the Scale of Practices and Behaviors of Institutionalized Elderly to Prevent Falls showed good internal consistency, revealing a good Cronbach's alpha for six items of the scale $(\alpha=0.881)$, and correlation values between each item with the total scale between 0.559 and $0.796^{13,16}$. All items presented a Cronbach's alpha without values lower than the total alpha value. We conducted homogeneity analysis through Pearson's correlation values of items and their pertaining dimension, excluding the item. These were superior to 0.559 (Table 1).

\section{Construct validity}

In the tested version, items organized themselves distributing loads by 1 factor explaining $63.450 \%$ of variance, with proper values of 3.807 , and loading values varied between 0.677 and 0.840 .

KMO values of 0.775 demonstrated a good relationship between variables. When associating a significance level of $\mathrm{p}<0.001$, the Barlett's test allowed hypothesis rejection that correlation results in the population are due to chance, concluding that variables are significantly correlated ${ }^{13}$.

Dimension 2: Safety practices and behaviors adopted by elderly

The second dimension had an Alpha's internal consistency $=0.817$, for 11 items. The item-total correlation varied between 0.367 and 0.588 , the Alpha without the item varied between 0.790 and 0.813 , a data discredited of good scale fidelity. We conducted homogeneity analysis through Pearson's correlations between items and their pertaining dimension, excluding the item. These were superior to 0.559 (Table 2).

Table 1. Person's correlation of items composing the communication dimension and Cronbach's alpha of items with the total, without the item

\begin{tabular}{|c|c|c|}
\hline Content of items & $\begin{array}{c}\text { Pearson's correlation of the } \\
\text { total without the item }\end{array}$ & $\begin{array}{c}\text { Cronbach's } \boldsymbol{\alpha} \text { without } \\
\text { the item }\end{array}$ \\
\hline I hear and talk with other elderly about fall risk factors & .559 & .880 \\
\hline Doctors alert me for fall risk & .791 & .842 \\
\hline Nurses alert me for fall risk & .796 & .841 \\
\hline Caregivers alert me about the fall risk & .754 & .849 \\
\hline I communicate with caregivers about fall risk factors & .580 & .879 \\
\hline I communicate with nurses about identified risk factors & .695 & .864 \\
\hline Total alpha & 0.881 & \\
\hline
\end{tabular}

Table 2. Pearson's correlations of items composing the safety dimension and Cronbach's alpha with the total, without the item

\begin{tabular}{|c|c|c|}
\hline Content of items & $\begin{array}{c}\text { Pearson's correlation of } \\
\text { total without the item }\end{array}$ & $\begin{array}{c}\text { Cronbach's } \boldsymbol{\alpha} \\
\text { without the item }\end{array}$ \\
\hline I try to be perseverant when choosing the best fall preventive measures & .481 & .802 \\
\hline I select adequate shoes for my feet & .477 & .802 \\
\hline I opt to wear closed shoes & .470 & .803 \\
\hline I opt to wear shoes with non-skid sole & .474 & .804 \\
\hline I organize my room's space to facilitate moving around it & .532 & .797 \\
\hline I remove obstacles that might interfere walking in the room & .588 & .790 \\
\hline I keep the bed wheels locked & .451 & .809 \\
\hline When I get out of bed, I sit at first, with my feet touching the ground, and I stand up & .367 & .813 \\
\hline I make sure that my feet are well supported on the ground before standing up & .514 & .800 \\
\hline I verify if the bathroom floor is not slippery/wet before using it & .494 & .801 \\
\hline Before hygiene care, I make sure the floor is not slippery & .522 & .798 \\
\hline
\end{tabular}


Table 3. Matrix of main components after Varimax rotation of 11 items of the Dimension Safety Practices and Behaviors adopted by elderly

\begin{tabular}{|c|c|c|c|}
\hline Content of items & $\mathbf{H 2}$ & F1 & F2 \\
\hline I select shoes adequate to my feet & .381 & .551 & \\
\hline I opt to wear closed shoes & .395 & .642 & \\
\hline I opt to wear closed shoes with non-skid sole & .419 & .646 & \\
\hline When I get out of bed, I sit at first, with my feet touching the ground, and I stand up after & .419 & .619 & \\
\hline I make sure that my feet are well supported on the ground before standing up & .502 & .663 & \\
\hline I verify if the bathroom floor is not slippery/wet before using it & .519 & .673 & \\
\hline Before hygiene care, I make sure that the floor is not slippery & .556 & .696 & \\
\hline I try to be perseverant when choosing the best preventive measures for falls & .355 & & .594 \\
\hline I organize my room's space to facilitate moving around it & .756 & & .846 \\
\hline I remove obstacles that might interfere walking in the room & .781 & & .853 \\
\hline I keep the bed wheels locked & .497 & & .717 \\
\hline$\%$ total explained variance & & & 50.341 \\
\hline$\%$ explained variance by factor & & 36.253 & 14.088 \\
\hline KMO & & 0.727 & \\
\hline Bartlett's Test of Sphericity & \multicolumn{3}{|c|}{$710.62 ; p<0.001$} \\
\hline
\end{tabular}

\section{Construct validity}

In the tested version, items were organized distributing loads by 2 factors explaining $50.341 \%$ of variance.

KMO values of 0.727 demonstrated a good correlation between variables, and because the Barlett's test was associated to a significance level of $p<0.001$, it allowed rejecting the hypothesis that correlation results in the population was due to chance, concluding that variables are significantly correlated ${ }^{13}$ (Table 3 ).

According with the expressed content in each factor, the following names were attributed: F1 - Safe practices in self-care, F2 - Accessibility practices in the physical space.

Communication practices and behaviors from the EAPCIP scores values varying between six and 30 points, and safety practices and behaviors adopted by elderly varies between 11 and 55 points.

\section{Discussion}

The scale presents psychometric characteristics with values considered good by reference authors ${ }^{13-16}$.

The dimension of communication practices and behaviors intend to measure the bilateral communication among elderly and professionals. Communication and fall report is a vital aspect for fall prevention ${ }^{3}$. The communication of fall risk factors and preventive measures for elderly is important due to the need to encourage institutionalized elderly to prevent fall episodes ${ }^{17}$ and to keep their independence for longer. This communication assumes an even higher importance because falls are undervalued by seniors, who do not report them in many occasions ${ }^{18}$.

The low health literacy of some participants indicated the clear need to invest in community training as well as health professionals, who should develop communication skills to help those with lower health literacy levels. Therefore, beyond recommending the training to focus on communication skills development, it should focus on comprehending cultural, gender, and age specificities in different groups ${ }^{19}$.

Notwithstanding low literacy, communication is a central element of a fall prevention program. The communication improvement between residents and professionals about preventive measures and health promotion can secure appropriate and specific interventions to decrease fall incidence ${ }^{8}$.

Safety practices and behaviors adopted by elderly have two factors. The first refers to safety practices for self-care, after validation, items presenting consistent values for assessment and discrimination of practices relates to choice of shoes, standing up from bed, the bathroom and shower use. The second refers to practices of accessibility to the physical space.

It is important to note that the investigation associated changes on feet and use of inappropriate shoes to the occurrence of falls ${ }^{3}$ and, many fall episodes occur in the bedroom and bathroom $^{3,20,21}$, while standing up/transferences ${ }^{3}$ and walking.

The fall during transfer from bed to wheelchair may be associated with a poor judgement of the chair height when sitting ${ }^{3}$, but also associated with risk factors in the physical space with slippery floor in the bathroom and in the shower. For these reasons, it is important to identify practices and behaviors of elderly during self-care, in physical spaces and in their perseverance when choosing preventive measures.

Based on psychometric characteristics and association of items with preventive measures to help to control main fall risks, this scale is more valid for assessing elderly practices and behaviors for fall prevention.

Prevention should be recognized as priority for investigation and intervention ${ }^{1}$. 


\section{Conclusions}

Above all active aging and the adoption of safe practices and behaviors is an individual accountability but fall prevention is a social and political responsibility determining the need for health policies with a focus on primary prevention, increased literacy in health and policies development that bet in maintaining security of the elderly in nursing homes The emergence of a prevalence decrease of falls is a challenge for health professionals to invest in prevention programs which takes account not only bio-physiological risk but also behavioral risk associated with the more or less safe elderly practices.

This phenomenon has been considered as a growing public health issue. The increase of elderly people and the perspective of prolonged life expectancy promotes falls, and with more severe consequences, not only by the higher probability of lesion, but also by repercussions on functionality.

Elderly involvement in prevention programs decreases the prevalence of falls, for this reason, it is important to assess elderly practices and behaviors regarding preventive measures.

We consider a necessity to deepen knowledge, practices, and behaviors of the elderly population who falls, to provide tools for professionals and improvement of provided care.

Risk factors, instruments for risk assessment, practices and behaviors, and preventive measures should be studied during nursing training.

The construction and validation of this scale allows to identify elderly practices and behaviors, and, to individualize interventions for controlling risk practices.

\section{REFERENCES}

[1] Wagner, L.M., Scott, V., Silver, M. Current approaches to fall risk assessment in nursing homes. GeriatrNurs. 2011; 32(4): 238-244.

[2] Bösner, S., Keller, H., Wöhner, C., Sönnichsen, A., Baum, E., Donner-Banzhoff, N. Prevention of falls by outdoor-walking in elderly persons at risk ("power")- a pilot study. European Geriatric medicine. 2012; 3: 28-32.

[3] Nitz, J., Cyarto, E., Adrews, S. et al. Outcomes from the implementation of a facility-specific evidence-based falls prevention intervention program in residential aged care. GeriatrNurs. 2012; 33(1): 41-50.

[4] Teresi, J.A., Ramirez, M., Remler, D. et al. Comparative effectiveness of implementing evidenced-based education and best pratices in nursing homes: effects on falls, quality-of-life and societal costs. International Journal of Nursing Studies. 2013; 50(4): 448-463.

[5] Leland, N.E. Gozalo, P.; Teno, J., Mor, V. Falls in Newly Admitted Nursing Home Residents: A National Study. JAGS.
2012; 60(5): 939-945.

[6] Becker, C.; Rapp, K. Fall preventing in nursing homes. Clinics in Geriatric Medicine. 2010; 26(4): 693-704.

[7] Baixinho C, Dixe M. a A. Fall risk factors valued By elderly and needs of education for prevention. Atencion Primaria. 2013; 45: 111 .

[8] Duffy, A. The assessment and management of falls in residential care settings. British Journal of Nursing. 2013; 22(5): 259-263.

[9] Hanson, H., Salmoni, A.W., Doyle, P.C. Broadening our understanding: Approaching falls as a stigmatizing topic for older adults. Disability and Health Journal. 2009; 2(1): 36-44.

[10] World Health Organization. WHO Global Report on Falls Prevention in Older Age. World Health Organization. Geneva; 2007.

[11] Guerreiro, M., Silva, A., Botelho, A., Leitão, O., Castro-Caldas, A., Garcia, C. Adaptação Portuguesa do Mini Miental State- MMS. Laboratório de Estudos de Linguagem do Centro de EstudosEgas Moniz. Lisboa; 1993.

[12] Hair, J.F., Tatham, R.L., Anderson, R.E., Black, W. Análise Multivariada de Dados. Bookman. Porto Alegre; 2005.

[13] Pestana, M. H., \&Gageiro, J. N. Análise de Dados para Ciências Sociais: a complementaridade do SPSS, 5. ${ }^{\mathrm{a}}$ ed. Edições Sílabo. Lisboa; 2008.

[14] Waltz, C., Strickland, O., Lenz, E. Measurement in Nursing and Health Research, 4th. Ed. Springer Publishing Company. New York; 2010.

[15] Almeida, L., Freire, T. Metodolgia da investigação em psicologia da educação, $5^{\mathrm{a}}$ ed. Psiquilibrios. Braga; 2007.

[16] Streiner, D.L., Norman, G.R. Health and Measurement Scales. A practical guide for their development and use, 4th ed. Oxford University Press. Oxford; 2008.

[17] Australian Commission on Safety and Quality in Health Care. Preventing falls and harm from falls in older people: Best Practice Guidelines for Australian Residential Aged Care Facilities. Australian Health Ministers. Austrália; 2009.

[18] Duarte, M.C. Caracterização e impacte das quedas de doentes, comoindicador de qualidade, num Hospital E.P.E. Dissertação de Mestrado em gestão da saúde, Escola Nacional de Saúde Pública. Portugal; 2011.

[19] World Health Organization. Health Literacy. The solid facts. World Health Organization. Geneva; 2013.

[20] Rapp, K., Becker, C., Cameron, I., Konig, H., Buchele, G. Epidemiology of falls in residential aged care:

[21] Analysis of more than 70,000 falls from residents of Bavarian nursing homes. $J$ Am Med Dir Assoc. 2012; 13(2):187.e1-187.e6.

[22] Álvares, L.M., Lima, R., Silva, R. Ocorrência de quedas em idosos residentes em instituições de longa permanência em Pelotas, Rio Grande do Sul, Brasil. Cad. Saúde Pública. 2010; 26(1):31-40. 